\title{
Synthesis of Polybenzoxazine/Clay Nanocomposites by In Situ Thermal Ring-Opening Polymerization Using Intercalated Monomer
}

\author{
Kubra Dogan Demir, ${ }^{1}$ Mehmet Atilla Tasdelen, ${ }^{1,2}$ Tamer Uyar, $^{3}$ Asei William Kawaguchi, ${ }^{4}$ \\ Atsushi Sudo, ${ }^{4}$ Takeshi Endo, ${ }^{4}$ Yusuf Yagci $^{1}$ \\ ${ }^{1}$ Department of Chemistry, Faculty of Science and Letters, Istanbul Technical University, Maslak TR-34469, Istanbul, Turkey \\ ${ }^{2}$ Department of Polymer Engineering, Faculty of Engineering, Yalova University, 77100 Yalova, Turkey \\ ${ }^{3}$ UNAM-Institute of Materials Science and Nanotechnology, Bilkent University, 06800 Ankara, Turkey \\ ${ }^{4}$ Molecular Engineering Institute, Kinki University, Kayanomori, lizuka 820-8555, Japan \\ Correspondence to: Y. Yagci (E-mail: yusuf@itu.edu.tr)
}

Received 31 March 2011; accepted 24 June 2011; published online 22 July 2011

DOI: $10.1002 /$ pola.24863

ABSTRACT: A new class of polybenzoxazine/montmorillonite (PBz/MMT) nanocomposites has been prepared by the in situ polymerization of the typical fluid benzoxazine monomer, 3-pentyl-5-ol-3,4-dihydro-1,3-benzoxazine, with intercalated benzoxazine MMT clay. A pyridine-substituted benzoxazine was first synthesized and quaternized by 11-bromo-1-undecanol and then used for ion exchange reaction with sodium ions in MMT to obtain intercalated benzoxazine clay. Finally, this organomodified clay was dispersed in the fluid benzoxazine monomers at different loading degrees to conduct the in situ thermal ring-opening polymerization. Polymerization through the interlayer galleries of the clay led to the PBz/MMT nano- composite formation. The morphologies of the nanocomposites were investigated by both $\mathrm{X}$-ray diffraction and transmission electron microscopic techniques, which suggested the partially exfoliated/intercalated structures in the PBz matrix. Results of thermogravimetric analysis confirmed that the thermal stability and char yield of $\mathrm{PBz}$ nanocomposites increased with the increase of clay content. (C) 2011 Wiley Periodicals, Inc. J Polym Sci Part A: Polym Chem 49: 4213-4220, 2011

KEYWORDS: benzoxazine resins; clay; high performance polymers; in situ polymerization; nanocomposites; polybenzoxazines; thermosets
INTRODUCTION Polybenzoxazine (PBz) is newly developed phenolic resin with interesting physical and mechanical properties. $^{1,2}$ Besides providing sophisticated features, these thermosets possess the excellent properties of traditional phenolic resins such as heat resistance, good electrical properties, and flame retardance. Conventional phenolic materials from either novolac or resole type resins suffer from the common shortcomings such as microvoid and byproduct formation and need harsh catalysts to initiate the polymerization. PBz not only overcomes these problems but also offers many advantages for use in electronic components, adhesives, coatings, composites, and among others. ${ }^{3-5}$ Many strategies have been developed with the aim of expanding the scope and circumventing the limitations of benzoxazine resin, especially in view of possible industrial applicability. These include (i) synthesis of benzoxazine monomers with additional functionality, ${ }^{6-16}$ (ii) incorporation of benzoxazine in polymer chains, ${ }^{17-31}$ and (iii) synthesis of benzoxazine-based composites or alloys. ${ }^{32-39}$

Polymer/clay nanocomposites have been studied extensively because a small amount of well-dispersed clay layers in the polymer matrix can improve its mechanical and thermal properties. $^{40-42}$ There are three methods for the preparation of polymer/clay nanocomposites: solution exfoliation, melt inter- calation, and in situ polymerization. ${ }^{43}$ In situ polymerization is the best and mostly used way to prepare the nanocomposites because these types of nanofillers and polymer precursors can be varied to get the enhanced properties. ${ }^{44-50} \mathrm{PBz} /$ montmorillonite (PBz/MMT) nanocomposites can be produced by either melt blending or solution mixing techniques using a PBz precursor and organically modified MMTs. ${ }^{15,35,51-57}$ However, these techniques do not yield well-dispersed homogeneous layered silicates in the PBz matrix due to the partial incompatibility of organomodified clays. In the present work, we synthesized a quaternary pyridine-functionalized benzoxazine, which can be directly intercalated into the silicate layers by ion exchange reaction. In situ polymerization of mixing intercalated and virgin fluid benzoxazine monomers leads to $\mathrm{PBz} / \mathrm{MMT}$ nanocomposites, which are formed by partially exfoliated/intercalated nanolayers in the polymer matrix.

\section{RESULTS AND DISCUSSION}

Synthesis and Quaternization of 6-Methyl-3-(pyridin-4yl)-3,4-dihydro-1,3-benzoxazine

Based on the fact that quaternized ammonium ions can exchange with sodium ions of clay, first benzoxazine monomer with a quaternizable moiety, namely 6-methyl-3- 


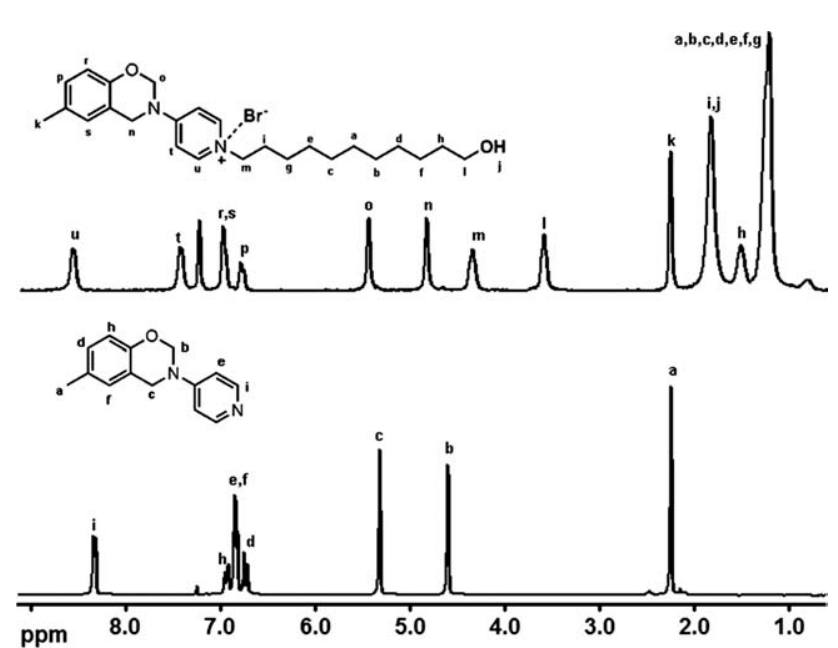

FIGURE $1{ }^{1} \mathrm{H}$ NMR spectra of BPy and qBPy monomers.

(pyridin-4-yl)-3,4-dihydro-1,3-benzoxazine (BPy), was synthesized by the reaction of pyridine-4-amine, $p$-cresol, and $p$-formaldehyde in the presence of acetic acid. As the quaternizable moiety, pyridine was deliberately selected so as to prevent possible side reactions during benzoxazine synthesis. For the successful synthesis of BPy, addition of acetic acid was essential. Without adding acetic acid, a complex mixture containing a small amount of BPy (less than $10 \%$ by ${ }^{1} \mathrm{H}$ NMR analysis) was obtained. This can be due to the high basicity of pyridine-4-amine, which can catalyze condensation of aromatic compounds (involving $p$-cresol and formed BPy) with formaldehyde. By adding acetic acid, the reaction system was neutralized, leading to the successful suppression of side reactions. At the same time, the reaction was retarded seriously. However, due to the absence of byproducts, purification was quite facile, just by removing unreacted pyridine-4-amine by column chromatography followed by recrystallization.

The structure of BPy was confirmed by spectral and thermal analyses. As can be seen from Figure 1 , the ${ }^{1} \mathrm{H}$ NMR spectrum exhibits not only the specific signals of the benzoxazine ring but also the chemical shifts of the pyridine group. Moreover, in the FTIR analysis of BPy, the characteristic bands at $1230 \mathrm{~cm}^{-1}$ (C-O-C), $1353 \mathrm{~cm}^{-1}\left(\mathrm{CH}_{2}\right.$ wagging), and 1506 and $980 \mathrm{~cm}^{-1}$ (trisubstituted benzene ring) confirms the benzoxazine ring formation. Absorption bands of pyridine group are typically located at $1597 \mathrm{~cm}^{-1}$ (aromatic mode).

The quaternization of BPy (qBPy) was carried out by 11bromo-1-undecanol, and its chemical structure was confirmed by both ${ }^{1} \mathrm{H}$ NMR and FTIR analyses (Scheme 1). As can be seen in Figure 1, typical $\left(\mathrm{CH}_{2}\right)$ protons of the aliphatic chain were appeared at 1-2 ppm, whereas $\left(\mathrm{CH}_{2}\right)$ protons of oxazine ring were shifted from 4.6 and 5.3 to 4.8 and

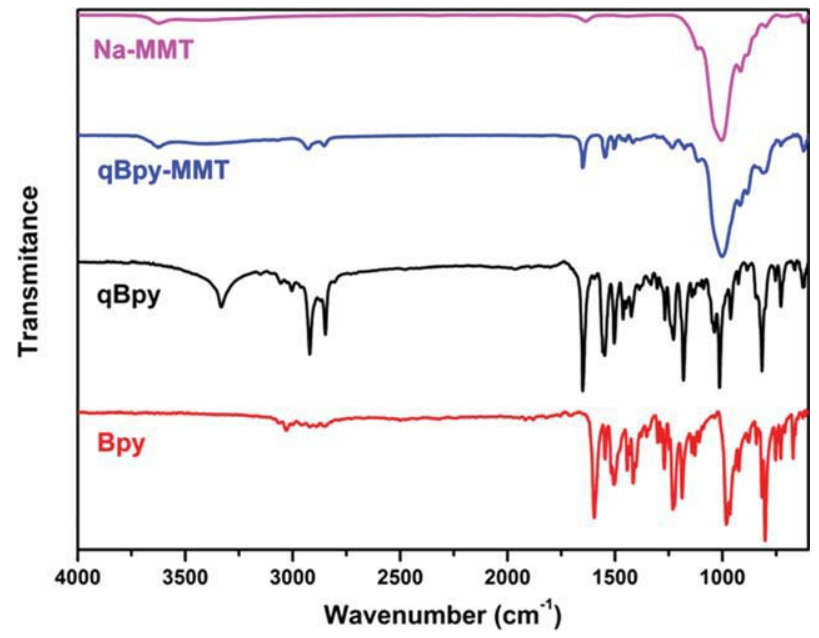

FIGURE 2 FTIR spectra of BPy and qBPy monomers, and qBPyMMT clay. [Color figure can be viewed in the online issue, which is available at wileyonlinelibrary.com.]

$5.5 \mathrm{ppm}$. The characteristic absorptions at 2922, 1506, and $1230 \mathrm{~cm}^{-1}$ are assigned to the $\mathrm{CH}_{2}$, aromatic ring, and $\mathrm{C}-\mathrm{O}-\mathrm{C}$ vibrations of benzoxazine structure, whereas the increase of peak at $2922 \mathrm{~cm}^{-1}$ indicates a successful quaternization of the benzoxazine monomer (Fig. 2).

\section{Preparation of Intercalated Monomer (qBPy-MMT)}

Organomodified clay (qBPy-MMT) was prepared by cationic exchange of sodium MMT (Na-MMT) with qBPy in distilled water at $50{ }^{\circ} \mathrm{C}$ (Scheme 2). The characteristic peaks of benzoxazine were remained, and a new peak at $1005 \mathrm{~cm}^{-1}$ was appeared due the $\mathrm{Si}-\mathrm{O}-\mathrm{Al}$ stretching of layered silicates. Gallery distances (basal space, $d_{001}$ ) of pure clay and organoclay (NaMMT and qBPy-MMT) were determined by X-ray diffraction (XRD) analysis (Fig. 3). The pristine clay sample exhibited a peak at $7.44^{\circ}$, which corresponded to a basal space $\left(d_{001}\right)$ of $1.18 \mathrm{~nm}$ and this peak shifted to $4.65^{\circ}$, which corresponded to $d_{001}$ of $1.88 \mathrm{~nm}$. This change indicated that the qBPy was successfully intercalated into the silicate galleries of the MMT clay. Larger interlayer spaces could help the diffusion of fluid benzoxazine monomers as well as the exfoliation of nanocomposites by providing more hydrophobic environment.

\section{Preparation of PBz/MMT Nanocomposites}

Fluid benzoxazine, 3-pentyl-5-ol-3, 4-dihydro-1, 3-benzoxazine, was deliberately chosen to enhance monomer diffusion into the clay interlayer. This monomer was blended with different intercalated clay loadings $(1,3,5$, and $10 \%$ by weight) by mechanical stirring. The cast films were cured at $240{ }^{\circ} \mathrm{C}$ for $3 \mathrm{~h}$ in air oven for the thermal ring-opening polymerization of benzoxazines. The growing PBz chains in the silicate

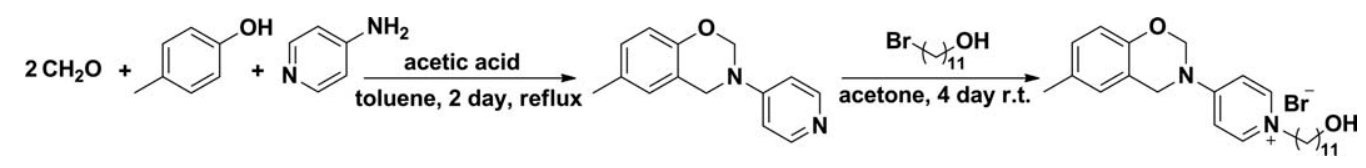

SCHEME 1 Synthesis and quaternization of 6-methyl-3-(pyridin-4-yl)-3,4-dihydro-1,3-benzoxazine. 


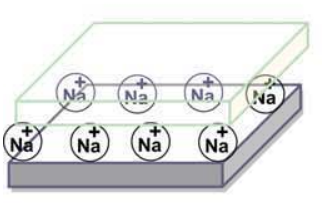

(Na-MMT)

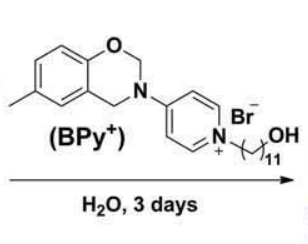

(qBPy-MMT)

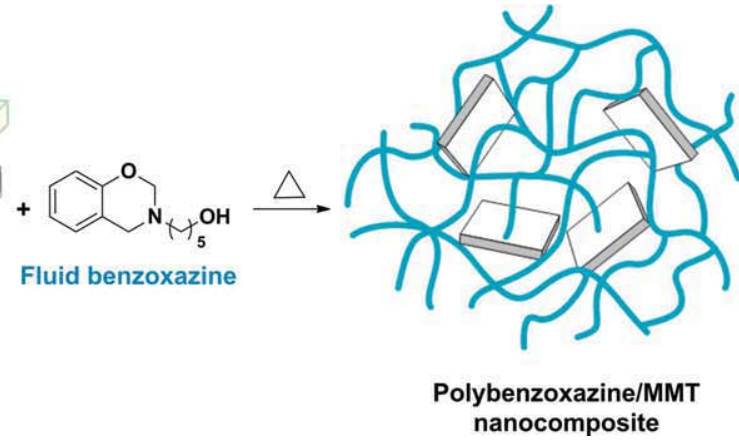

SCHEME 2 Intercalation of qBPy-MMT and preparation of PBz/MMT nanocomposites. [Color figure can be viewed in the online issue, which is available at wileyonlinelibrary.com.]

layers led to the clay exfoliation as well as the nanocomposite formation (Scheme 2).

XRD patterns for the PBz/MMT nanocomposites formed by varying the clay contents were shown in Figure 3. After the polymerization, the diffraction peak at $4.65^{\circ}$ was completely disappeared in the nanocomposite sample containing $1 \%$ clay loading, whereas this peak was remained in three nanocomposite samples containing 3, 5, and10 \% clay loading. These data suggested that nanocomposites with higher clay loading than $1 \%$ have partially intercalated structures, however, XRD measurements alone are not conclusive for determining the true structures and distributions of the silica platelets; thus, we turn our attention to transmission electron microscopic measurements. Figure 4 displays TEM images of all nanocomposites. The dark lines represent the silicate layers; about 1.0 nm thick and from 50 to $100 \mathrm{~nm}$ in lateral dimension, which are oriented perpendicularly to the slicing plane. The platelet layers for the both nanocomposite samples are a mixture of fully exfoliated (white circles) and intercalated (white squares) structures. Although the XRD showed no peak for nanocomposite with $1 \%$ clay loading, the TEM revealed a

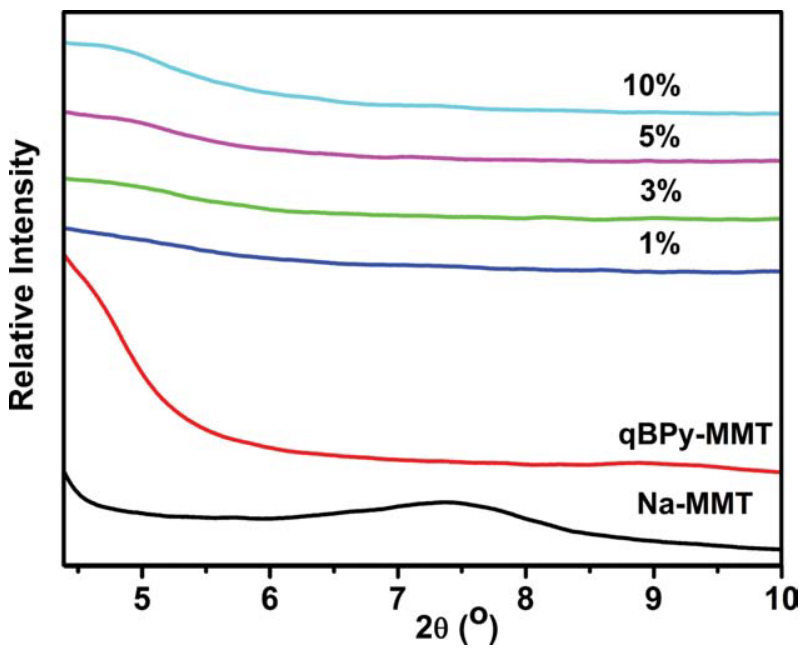

FIGURE 3 XRD patterns of Na-MMT, qBPy-MMT, and PBz/MMT nanocomposites containing 1, 3, 5, and $10 \%$ clay. [Color figure can be viewed in the online issue, which is available at wileyonlinelibrary.com.] mixture of intercalated and exfoliated structures in the nanocomposite. Based on the XRD and TEM results, it could be concluded that partially exfoliated/intercalated structures were achieved in all PBz/MMT nanocomposites.

\section{Thermal Behavior}

Thermal behavior of starting materials, BPy, qBPy, and qBPyMMT, was investigated by DSC, and the profiles were shown in Figure 5. The BPy monomer exhibited two endothermic and one exothermic peaks corresponding two different crystal structures or liquid crystalline behavior in the molten state and ring-opening reaction. After quaternization, qBPy, the exothermic polymerization peak with maximum at $303{ }^{\circ} \mathrm{C}$ was broadened toward low temperature onset, whereas thermal activation temperature slightly decreased due to the presence of alcohol group. ${ }^{58-60}$ This tendency was in good agreement with the behavior of alkyl substituent on para-position of arylamine-based benzoxazine in the literature. ${ }^{61}$ DSC thermogram of qBPy-MMT indicates a much broader exotherm at $303{ }^{\circ} \mathrm{C}$ because of the catalytic effect of the silicate layers on the ring-opening polymerization of benxozazine.

The catalytic effect of clay content on the ring-opening behavior of benzoxazines was also investigated by DSC studies using various qBPy-MMT loadings. An exothermic peak of ring opening of fluid benzoxazine in the absence of clay was detected starting from $200{ }^{\circ} \mathrm{C}$ with maximum at $256{ }^{\circ} \mathrm{C}$, while onset and maximum temperatures of benzoxazine with 5\% Na-MMT shifted to lower temperatures 195 and $251{ }^{\circ} \mathrm{C}$, respectively (Fig. 6). The similar trend along with the increase of clay content was also observed in the qBPy-MMT samples (Fig. 7). ${ }^{53}$ Moreover, even 1\% of qBPy-MMT clay was enough to lower the polymerization temperature of the fluid benzoxazine.

The cure progress of benzoxazine loading with 10\% qBPyMMT sample was examined by varying curing temperature using both DSC and FTIR measurements. As shown in Figure 8 , the uncured blend exhibits three broad exotherms with maximum temperatures at 206, 255, and $300{ }^{\circ} \mathrm{C}$. The low temperature exotherm, which is centered at $206{ }^{\circ} \mathrm{C}$, can be explained as the accelerated ring opening of oxazine by protons of alcohol functionality. ${ }^{58}$ After curing at $150{ }^{\circ} \mathrm{C}$, this peak disappeared completely, whereas the main benzoxazine 

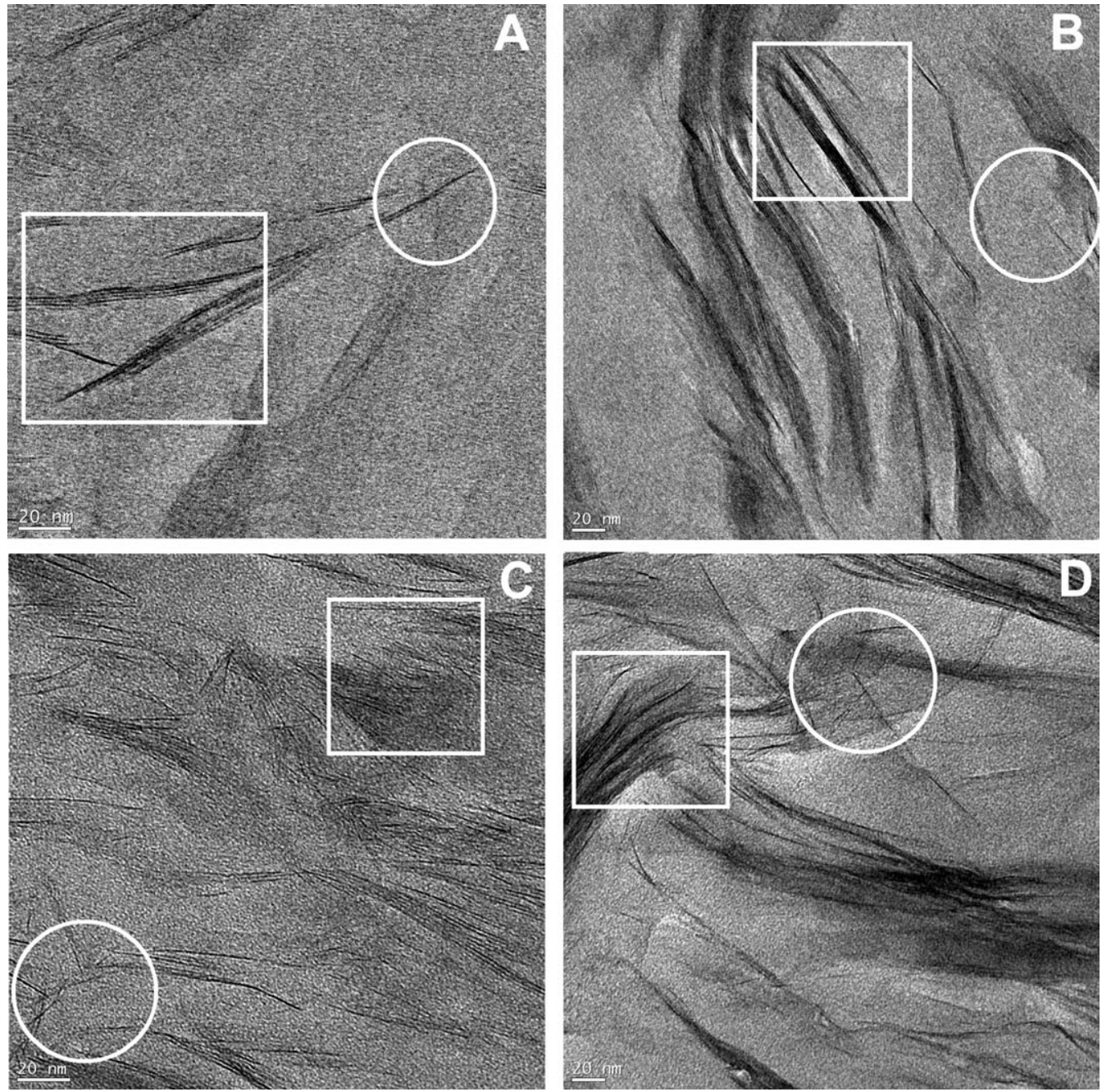

FIGURE 4 TEM images of PBz/MMT nanocomposites loading with (A) 1, (B) 3, (C) 5, and (D) 10\% (B) qBPy-MMT clay.

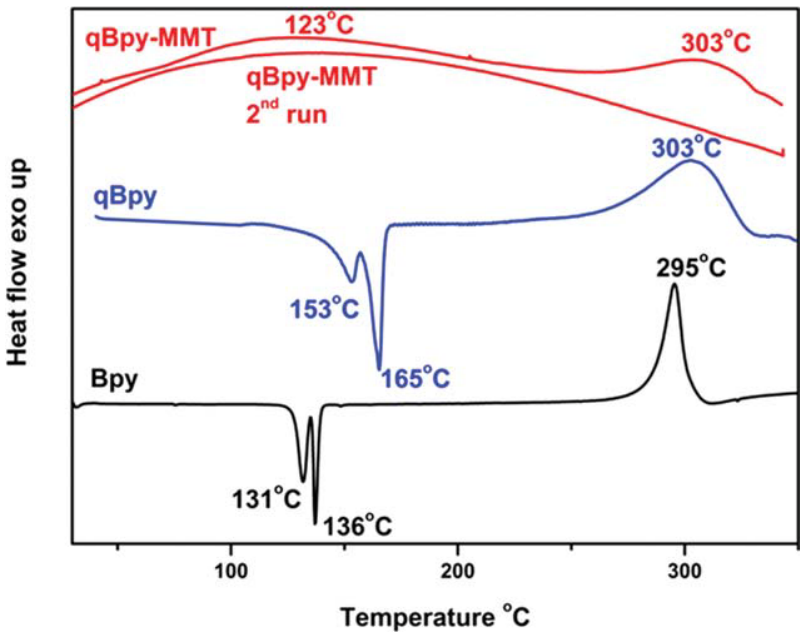

FIGURE 5 DSC thermograms of BPy, qBPy, and qBPy-MMT. [Color figure can be viewed in the online issue, which is available at wileyonlinelibrary.com.]

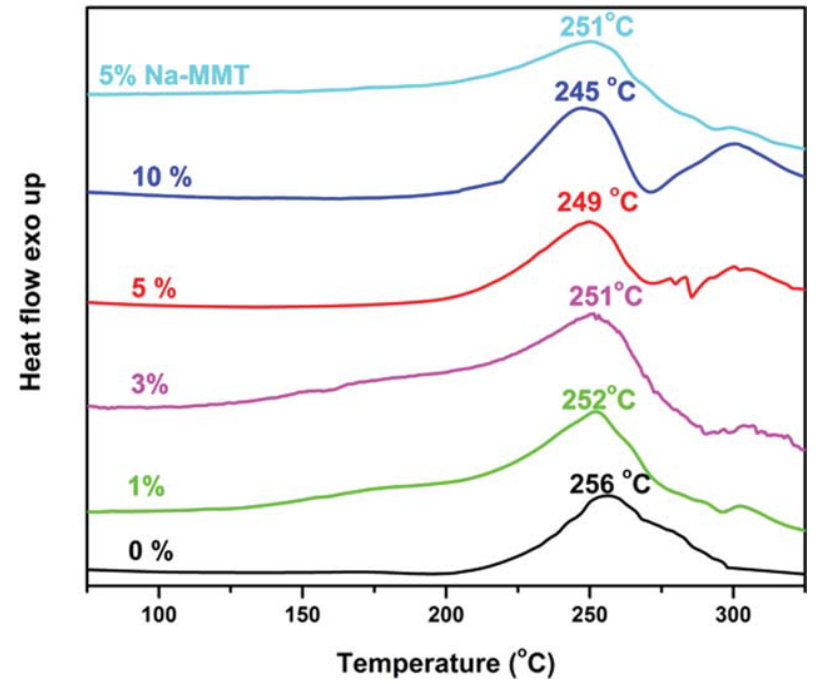

FIGURE 6 DSC thermograms of fluid benzoxazine with different qBPy-MMT loading (0, 1, 3, 5, and 10\%) and 5\% Na-MMT after cured at $150{ }^{\circ} \mathrm{C}$ for $1 \mathrm{~h}$. [Color figure can be viewed in the online issue, which is available at wileyonlinelibrary.com.] 


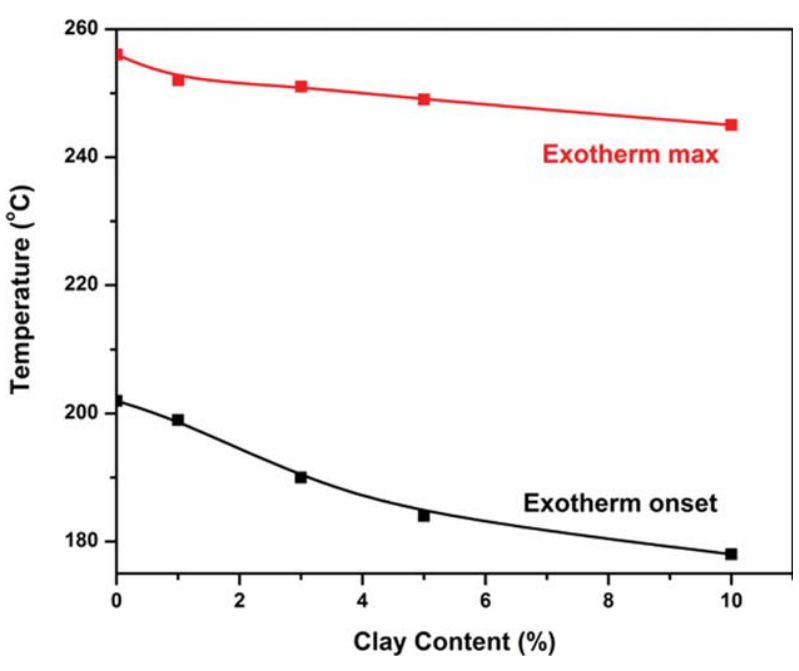

FIGURE 7 The catalytic effect of qBPy-MMT on the ring-opening polymerization temperatures. [Color figure can be viewed in the online issue, which is available at wileyonlinelibrary.com.]

exotherm decreased gradually by increasing cure temperature and almost completed at $260{ }^{\circ} \mathrm{C}$.

The FTIR spectra of fluid benzoxazine loaded with 10\% qBPyMMT after various curing stages were shown in Figure 9. Decrease of characteristic absorption bands of benzoxazine with higher cure temperature was observed at 1502 and $963 \mathrm{~cm}^{-1}$ (trisubstituted benzene), $1362 \mathrm{~cm}^{-1}\left(\mathrm{CH}_{2}\right.$ of benzoxazine ring), and $1225 \mathrm{~cm}^{-1}$ (ether linkage of benzoxazine). Besides, a new peak was appeared at $1472 \mathrm{~cm}^{-1}$ due to the tetrasubstituted benzene ring, suggesting that the ring opening took place to afford PBz. The absorption at $1002 \mathrm{~cm}^{-1}$ presented in all stages clearly indicated that the incorporation of a layered silicates framework into PBz network. Moreover, Figure 9 also showed the presence of aliphatic absorption peaks even at $260{ }^{\circ} \mathrm{C}$ curing temperature.

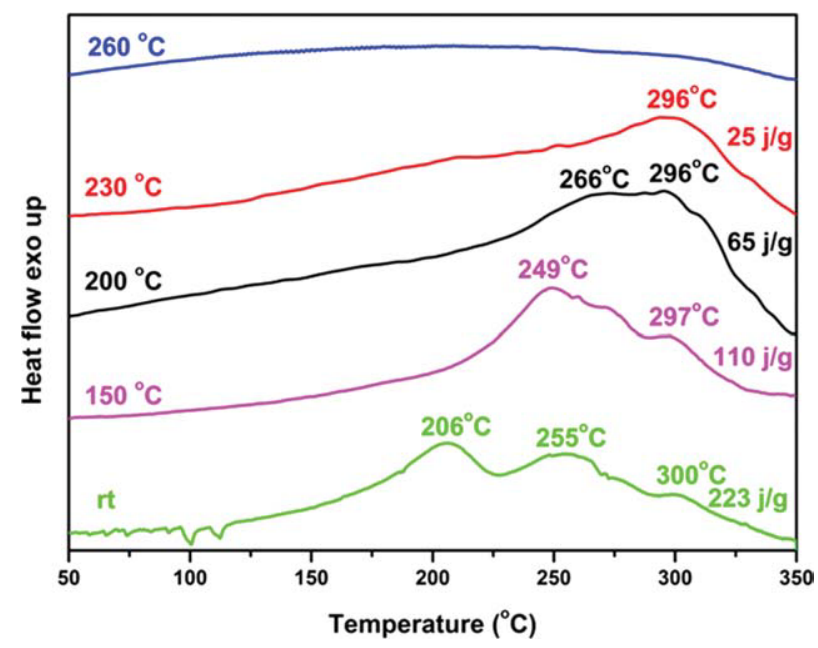

FIGURE 8 DSC thermograms of fluid benzoxazine loading with $10 \%$ qBPy-MMT at different curing temperatures for $1 \mathrm{~h}$. [Color figure can be viewed in the online issue, which is available at wileyonlinelibrary.com.]

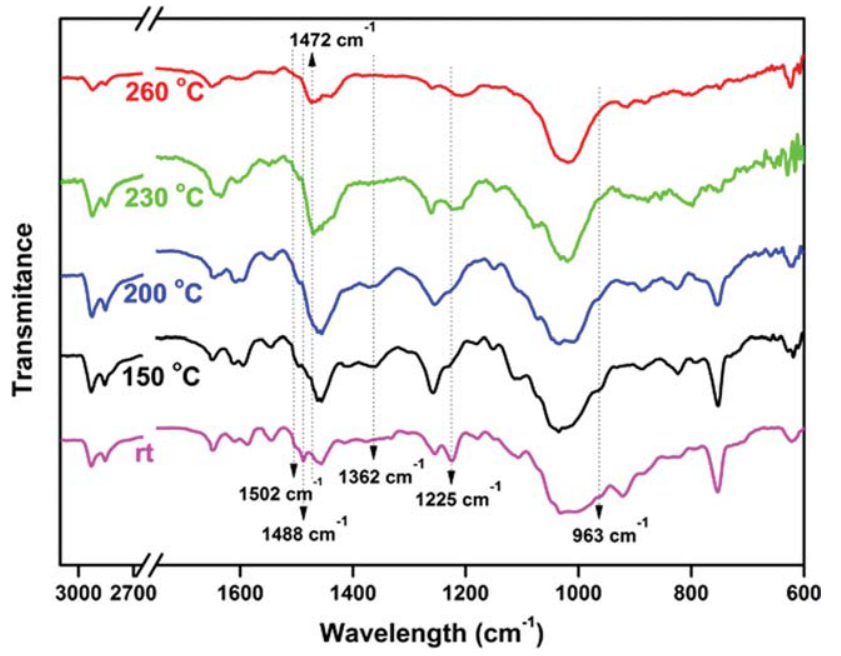

FIGURE 9 FTIR spectra of fluid benzoxazine loading with $10 \%$ qBPy-MMT at different curing temperatures for $1 \mathrm{~h}$. [Color figure can be viewed in the online issue, which is available at wileyonlinelibrary.com.]

Thermal gravimetric analyses were also performed to examine the thermal stability of PBz/MMT nanocomposites. Typical TGA curves for virgin $\mathrm{PBz}$ and its nanocomposites were shown in Figure 10, and the overall results were converted into weight residue at different temperatures versus clay content (Fig. 11). Although the degradation onset of the nanocomposites was improved by the inclusion of the qBPyMMT, the clay content did not affect the first degradation temperature of the nanocomposites. But, the thermal stabilities of the nanocomposites were increased by clay contents at elevated temperatures. This behavior was clearly realized when $60 \%$ weight loss occurred with different clay contents. The $60 \%$ weight loss for the nanocomposites containing 5 and $10 \%$ qBPy-MMT was detected at 476 and $556^{\circ} \mathrm{C}$.

The weight loss temperatures of PBz/MMT nanocomposites with various clay contents were also summarized in Table 1. The char yield at $900{ }^{\circ} \mathrm{C}$ is increased from 16 to $35 \%$ by increasing qBPy-MMT contents in the nanocomposites. It can be concluded that all PBz/MMT nanocomposites exhibited a delayed decomposition behavior compared with the neat $\mathrm{PBz}$ resin.

\section{EXPERIMENTAL}

\section{Materials}

Na-MMT (Cloisite $\mathrm{Na}^{+}$) was purchased from Southern Clay products with cation exchange capacity (CEC) of 92.6 mequiv/100 g and used as received. $p$-Cresol (99\%; Wako Pure Chemical Industries), pyridine-4-amine (99\%; Tokyo Chemical Industry), $p$-formaldehyde (95\%; J.T. Baker), acetic acid (99.7\%; Wako Pure Chemical Industries), 11-bromo-1undecanol (96\%; Alfa Aesar), sodium hydroxide (99\%; Riedel-de Haen), anhydrous magnesium sulphate (99.5\%; Alfa Aesar), 1,4-dioxane ( $\geq 99 \%$; Aldrich), chloroform (99+\%; Acros), and $n$-hexane (95\%; Carlo Erba) were used as received. Acetone (99\%; Carlo Erba) was purified by 


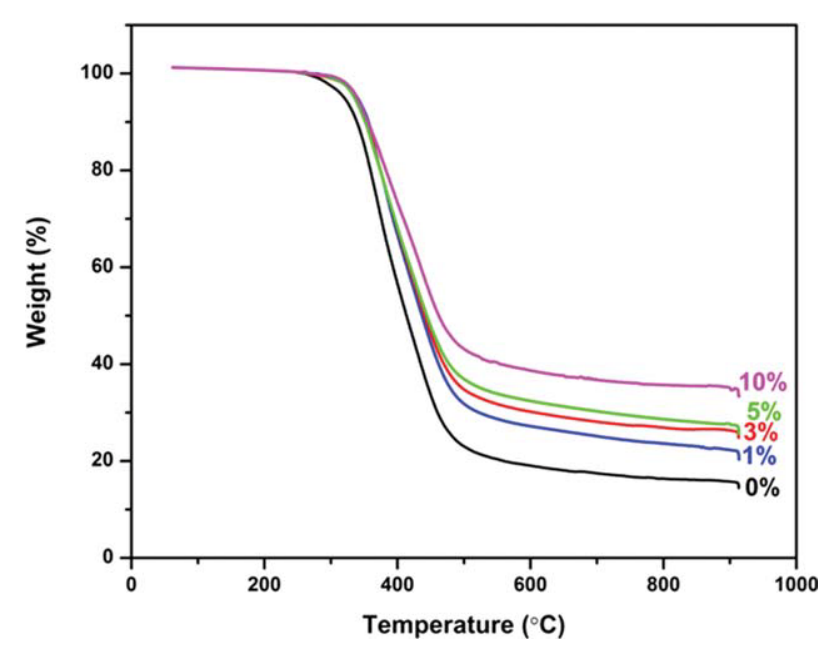

FIGURE 10 TGA of virgin polybenzoxazine and corresponding nanocomposites containing 1, 3, 5, and $10 \%$ clay. [Color figure can be viewed in the online issue, which is available at wileyonlinelibrary.com.]

distillation over calcium hydride. 3-Pentyl-5-ol-3,4-dihydro1,3-benzoxazine was synthesized as described previously from phenol, $p$-formaldehyde, and 5-amino-1-pentanol. ${ }^{59,60}$

\section{Synthesis of BPy}

In a 100-mL round-bottomed flask, pyridine-4-amine (940 mg, $10 \mathrm{mmol}$ ), $p$-cresol (1.08 g, $10 \mathrm{mmol}$ ), acetic acid (0.60 g, $10 \mathrm{mmol}$ ), paraformaldehyde (purity 95\%, $6.3 \mathrm{~g}$, $20 \mathrm{mmol})$, and toluene $(50 \mathrm{~mL})$ were placed and heated with refluxing for $48 \mathrm{~h}$. After cooling to room temperature, the reaction mixture was washed with $1.5 \mathrm{M} \mathrm{NaOH}$ aq. (100 mL, three times) and brine (100 mL, three times). The organic layer was dried over anhydrous $\mathrm{MgSO}_{4}$, filtered, and concentrated under reduced pressure. The resulting residue was then fractionated by silica gel column chromatography

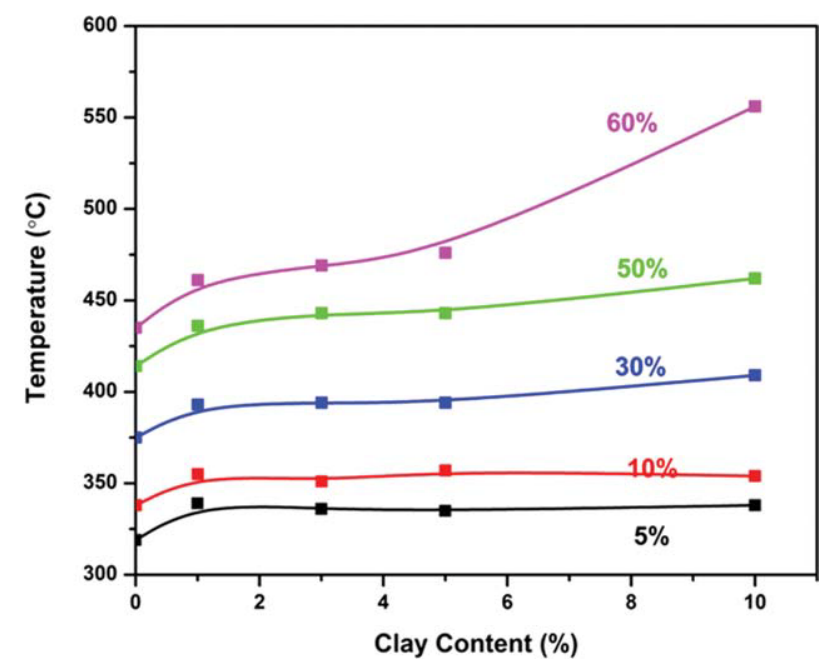

FIGURE 11 The effect of the qBPy-MMT content on decomposition temperatures of $\mathrm{PBz} / \mathrm{MMT}$ nanocomposites after curing at $240{ }^{\circ} \mathrm{C} / 3 \mathrm{~h}$
TABLE 1 Thermal Stability of PBz/MMT Nanocomposites After Curing at $240{ }^{\circ} \mathrm{C} / 3 \mathrm{~h}$

\begin{tabular}{llll}
$\begin{array}{l}\text { qBPy-MMT } \\
\text { Content }(\%)\end{array}$ & $T_{5 \%}\left({ }^{\circ} \mathrm{C}\right)$ & $T_{10 \%}\left({ }^{\circ} \mathrm{C}\right)$ & Char $\%$ at $900{ }^{\circ} \mathrm{C}$ \\
\hline 0 & 319 & 338 & 16 \\
1 & 339 & 355 & 22 \\
3 & 336 & 351 & 26 \\
\hline 5 & 335 & 351 & 28 \\
10 & 338 & 354 & 35 \\
\hline
\end{tabular}

$T_{5 \%}$ : The temperature which the weight loss is $5 \%$.

$T_{10 \%}$ : The temperature which the weight loss is $10 \%$.

Char \%: Char yields at $900{ }^{\circ} \mathrm{C}$ under nitrogen atmosphere.

with using acetone as an eluent to obtain crude BPy as a yellow solid. Recrystallization of the crude BPy from a mixture of acetone and $n$-hexane (volume ratio $=1: 4$ ) gave $\mathrm{BPy}$ : Yield: 30\%. m.p.: 131, $136{ }^{\circ} \mathrm{C}$.

FTIR (ATR, $\mathrm{cm}^{-1}$ ): $v=3028,1597,1506,1443,1353,1230$, 980, 963, 924, 801. ${ }^{1} \mathrm{H}$ NMR (250 MHz, $\left.\mathrm{CDCl}_{3}, \delta, \mathrm{ppm}\right): 2.25$ $(\mathrm{s}, 3 \mathrm{H}), 4.60(\mathrm{~s}, 2 \mathrm{H}), 5.32(\mathrm{~s}, 2 \mathrm{H}), 6.73(\mathrm{~d}, 1 \mathrm{H}), 6.83(\mathrm{~m}, 3 \mathrm{H})$, $6.93(\mathrm{~d}, 1 \mathrm{H}), 8.33(\mathrm{~d}, 2 \mathrm{H})$.

\section{Quaternization of BPy}

In a $25-\mathrm{mL}$ round-bottomed flask, $150 \mathrm{mg}(0.66 \mathrm{mmol})$ of BPy and $167 \mathrm{mg}(0.66 \mathrm{mmol})$ of 11-bromodecane-1-ol were dissolved in $5 \mathrm{~mL}$ acetone and stirred at room temperature for 4 days. The crude product was collected as white precipitate by filtration and recrystallized from $n$-hexane affording to qBPy: Yield: $60 \%$. m.p.: $153,165^{\circ} \mathrm{C}$.

FTIR (ATR, $\mathrm{cm}^{-1}$ ): $v=3329,2922,2849,1650,1550,1506$, 1463, 1332, 1230, 963, 927, 816. ${ }^{1} \mathrm{H}$ NMR (250 MHz, $\mathrm{CDCl}_{3}$, $\delta, \mathrm{ppm}): 1.22(\mathrm{~s}, 14 \mathrm{H}), 1.52(\mathrm{~s}, 2 \mathrm{H}), 1.84(\mathrm{~s}, 3 \mathrm{H}), 2.27$ $(\mathrm{s}, 3 \mathrm{H}), 3.60(\mathrm{~s}, 2 \mathrm{H}), 4.36(\mathrm{~s}, 2 \mathrm{H}), 4.84(\mathrm{~s}, 2 \mathrm{H}), 5.46(\mathrm{~s}, 2 \mathrm{H})$, $6.79(\mathrm{~d}, 1 \mathrm{H}), 6.99(\mathrm{~s}, 2 \mathrm{H}), 7.44(\mathrm{~s}, 2 \mathrm{H}), 8.59$ (s, 2H).

\section{Preparation of Intercalated Monomer (qBPy-MMT)}

An aqua solution was prepared by dissolving $120 \mathrm{mg}, 0.251$ mmol of qBPy in 40 - $\mathrm{mL}$ distilled water and heated to $50{ }^{\circ} \mathrm{C}$ for 1 day. To this solution, a suspension of $181 \mathrm{mg}$ of $\mathrm{Na}$ MMT in $30 \mathrm{~mL}$ distilled water was added. The mixture was diluted to $400 \mathrm{~mL}$ and stirred for 2 days, and the resultant precipitate was collected by filtration. The filtrate was washed with hot water several times and once with methanol and dried in vacuum: Yield: 68\%.

\section{Preparation of PBz/MMT Nanocomposites}

Various amounts of qBPy-MMT $(1,3,5$, and $10 \%$ by weight) was added to the 3-pentyl-5-ol-3,4-dihydro-1,3-benzoxazine on a glass plate that was pretreated with dichloromethylsilane. The blends were mechanically stirred at $50{ }^{\circ} \mathrm{C}$ and cured at $240{ }^{\circ} \mathrm{C}$ for $3 \mathrm{~h}$ each in air oven to form nanocomposites.

\section{Characterization}

${ }^{1} \mathrm{H}$ NMR measurements were recorded in $\mathrm{CDCl}_{3}$ with $\mathrm{Si}\left(\mathrm{CH}_{3}\right)_{4}$ as internal standard, using a Bruker AC250 (250.133 MHz) instrument. FTIR spectra were recorded on a 
Perkin-Elmer FTIR One-B spectrometer. The powder XRD measurements were performed on a PANalytical X'Pert PRO $\mathrm{X}$-ray diffractometer equipped with graphite-monochromatized $\mathrm{CuK} \alpha$ radiation $(\lambda=1.15 \AA$ ) . Differential scanning calorimetry (DSC) was performed on Perkin-Elmer Diamond DSC with a heating rate of $20{ }^{\circ} \mathrm{C} / \mathrm{min}$ under nitrogen flow (20 $\mathrm{mL} / \mathrm{min})$. Thermogravimetric analysis (TGA) was performed on Perkin-Elmer Diamond TA/TGA with a heating rate of $10{ }^{\circ} \mathrm{C} / \mathrm{min}$ under nitrogen flow (200 mL/min). TEM imaging of the samples was carried out by FEI Tecnai ${ }^{\mathrm{TM}} \mathrm{G}^{2}$ F30 instrument operating at an acceleration voltage of $200 \mathrm{kV}$. About 100-nm ultrathin TEM specimens were cut by using cryo-ultramicrotome (EMUC6 + EMFC6, Leica) equipped with a diamond knife. The ultrathin samples were placed on copper grids for TEM analyses.

\section{CONCLUSIONS}

In conclusion, PBz/MMT nanocomposites have been prepared by the in situ thermal ring-opening polymerization of the fluid benzoxazine with intercalated benzoxazine monomers. The organomodified clay can be readily obtained from the structurally designed benzoxazine monomer. Thermal ring-opening polymerization of benzoxazines through the interlayer galleries leads to nanocomposites formations, which are formed by individually dispersing inorganic silica nanolayers in the polymer matrix. In terms of morphology, partially intercalated/exfoliated nanocomposites are evidenced by both the XRD and TEM measurements. DSC studies indicate that the ring opening of the benzoxazines in the presence of clay to form the nanocomposites occurs at relatively lower temperatures. All nanocomposites have higher thermal stabilities relative to that of the neat PBz. The char yields increased on increasing the clay content.

The authors thank Istanbul Technical University Research Fund and Turkish Scientific and Technological Council (TUBITAK110T723) for financial supports and Y. Yagci thank Turkish Academy of Sciences (TUBA). They also thank N. Bulutcu for $\mathrm{X}$-ray measurements.

\section{REFERENCES AND NOTES}

1 Ghosh, N. N.; Kiskan, B.; Yagci, Y. Prog Polym Sci 2007, 32, 1344-1391.

2 Yagci, Y.; Kiskan, B.; Ghosh, N. N. J Polym Sci Part A: Polym Chem 2009, 47, 5565-5576.

3 Ishida, H.; Low, H. Y. Macromolecules 1997, 30, 1099-1106.

4 Ishida, H.; Allen, D. J. J Polym Sci Part B: Polym Phys 1996, 34, 1019-1030.

5 Ning, X.; Ishida, H. J Polym Sci Part A: Polym Chem 1994, $32,1121-1129$.

6 Lin, C. H.; Lin, H. T.; Chang, S. L.; Hwang, H. J.; Hu, Y. M.; Taso, Y. R.; Su, W. C. Polymer 2009, 50, 2264-2272.

7 Jin, L.; Agag, T.; Ishida, H. Eur Polym J 2010, 46, 354-363.

8 Oie, H.; Sudo, A.; Endo, T. J Polym Sci Part A: Polym Chem 2010, 48, 5357-5363.
9 Sudo, A.; Du, L. C.; Hirayama, S.; Endo, T. J Polym Sci Part A: Polym Chem 2010, 48, 2777-2782.

10 Espinosa, M. A.; Cadiz, V.; Galia, M. J Polym Sci Part A: Polym Chem 2004, 42, 279-289.

11 Espinosa, M. A.; Galia, M.; Cadiz, V. Polymer 2004, 45, 6103-6109.

12 Sponton, M.; Larrechi, M. S.; Ronda, J. C.; Galia, M.; Cadiz, V. J Polym Sci Part A: Polym Chem 2008, 46, 7162-7172.

13 Andreu, R.; Espinosa, M. A.; Galia, M.; Cadiz, V.; Ronda, J. C.; Reina, J. A. J Polym Sci Part A: Polym Chem 2006, 44, 1529-1540.

14 Agag, T.; Takeichi, T. Macromolecules 2001, 34, 7257-7263.

15 Takeichi, T.; Zeidam, R.; Agag, T. Polymer 2002, 43, 45-53.

16 Agag, T.; Takeichi, T. Macromolecules 2003, 36, 6010-6017.

17 Kiskan, B.; Gacal, B.; Tasdelen, M. A.; Colak, D.; Yagci, Y. Macromol Symp 2006, 245, 27-33.

18 Kiskan, B.; Colak, D.; Muftuoglu, A. E.; Cianga, I.; Yagci, Y. Macromol Rapid Commun 2005, 26, 819-824.

19 Tasdelen, M. A.; Kiskan, B.; Yagci, Y. Macromol Rapid Commun 2006, 27, 1539-1544.

20 Kiskan, B.; Yagci, Y.; Ishida, H. J Polym Sci Part A: Polym Chem 2008, 46, 414-420.

21 Nagai, A.; Kamei, Y.; Wang, X. S.; Omura, M.; Sudo, A.; Nishida, H.; Kawamoto, E.; Endo, T. J Polym Sci Part A: Polym Chem 2008, 46, 2316-2325.

22 Velez-Herrera, P.; Doyama, K.; Abe, H.; Ishida, H. Macromolecules 2008, 41, 9704-9714.

23 Chernykh, A.; Agag, T.; Ishida, H. Polymer 2009, 50, 382-390.

24 Chernykh, A.; Agag, T.; Ishida, H. Macromolecules 2009, 42, 5121-5127.

25 Aydogan, B.; Sureka, D.; Kiskan, B.; Yagci, Y. J Polym Sci Part A: Polym Chem 2010, 48, 5156-5162.

26 Ergin, M.; Kiskan, B.; Gacal, B.; Yagci, Y. Macromolecules 2007, 40, 4724-4727.

27 Kiskan, B.; Demiray, G.; Yagci, Y. J Polym Sci Part A: Polym Chem 2008, 46, 3512-3518.

28 Kiskan, B.; Aydogan, B.; Yagci, Y. J Polym Sci Part A: Polym Chem 2009, 47, 804-811.

29 Kukut, M.; Kiskan, B.; Yagci, Y. Des Monomers Polym 2009, 12, 167-176.

30 Demir, K. D.; Kiskan, B.; Yagci, Y. Macromolecules 2011, 44, 1801-1807.

31 Altinkok, C.; Kiskan, B.; Yagci, Y. J Polym Sci Part A: Polym Chem 2011, 49, 2445-2450.

32 Kiskan, B.; Ghosh, N. N.; Yagci, Y. Polym Int 2011, 60, 167-177.

33 Shen, S. B.; Ishida, H. Polym Compos 1996, 17, 710-719.

34 Kiskan, B.; Demirel, A. L.; Kamer, O.; Yagci, Y. J Polym Sci Part A: Polym Chem 2008, 46, 6780-6788.

35 Agag, T.; Takeichi, T. High Perform Polym 2002, 14, 115-132.

36 Takeichi, T.; Guo, Y.; Rimdusit, S. Polymer 2005, 46, 4909-4916.

37 Agag, T.; Tsuchiya, H.; Takeichi, T. Polymer 2004, 45, 7903-7910.

38 Takeichi, T.; Guo, Y. J Appl Polym Sci 2003, 90, 4075-4083.

39 Takeichi, T.; Agag, T.; Zeidam, R. J Polym Sci Part A: Polym Chem 2001, 39, 2633-2641.

40 Ray, S. S.; Okamoto, M. Prog Polym Sci 2003, 28, 1539-1641.

41 Giannelis, E. P. Adv Mater 1996, 8, 29-35. 
42 Alexandre, M.; Dubois, P. Mater Sci Eng R 2000, 28, 1-63. 43 Pavlidou, S.; Papaspyrides, C. D. Prog Polym Sci 2008, 33, 1119-1198.

44 Tasdelen, M. A.; Kreutzer, J.; Yagci, Y. Macromol Chem Phys 2010, 211, 279-285.

45 Yenice, Z.; Tasdelen, M. A.; Oral, A.; Guler, C.; Yagci, Y. J Polym Sci Part A: Polym Chem 2009, 47, 2190-2197.

46 Oral, A.; Tasdelen, M. A.; Demirel, A. L.; Yagci, Y. J Polym Sci Part A: Polym Chem 2009, 47, 5328-5335.

47 Oral, A.; Tasdelen, M. A.; Demirel, A. L.; Yagci, Y. Polymer 2009, 50, 3905-3910.

48 Akat, H.; Tasdelen, M. A.; Du Prez, F.; Yagci, Y. Eur Polym J 2008, 44, 1949-1954.

49 Tasdelen, M. A.; Van Camp, W.; Goethals, E.; Dubois, P.; Du Prez, F.; Yagci, Y. Macromolecules 2008, 41, 6035-6040.

50 Nese, A.; Sen, S.; Tasdelen, M. A.; Nugay, N.; Yagci, Y. Macromol Chem Phys 2006, 207, 820-826.

$51 \mathrm{Fu}$, H. K.; Huang, C. F.; Kuo, S. W.; Lin, H. C.; Yei, D. R.; Chang, F. C. Macromol Rapid Commun 2008, 29, 1216-1220.
52 Chen, Q. A.; Xu, R. W.; Yu, D. S. J Appl Polym Sci 2006, 100, 4741-4747.

53 Agag, T.; Taepaisitphongse, V.; Takeichi, T. Polym Compos 2007, 28, 680-687.

54 Shi, Z. X.; Yu, D. S.; Wang, Y. Z.; Xu, R. W. J Appl Polym Sci 2003, 88, 194-200.

55 Yei, D. R.; Fu, H. K.; Chen, W. Y.; Chang, F. C. J Polym Sci Part B: Polym Phys 2006, 44, 347-358.

56 Phiriyawirut, P.; Magaraphan, R.; Ishida, H. Mater Res Innovations 2001, 4, 187-196.

57 Agag, T.; Takeichi, T. Polym Compos 2008, 29, 750-757.

58 Kudoh, R.; Sudo, A.; Endo, T. Macromolecules 2010, 43, $1185-1187$.

59 Tuzun, A.; Kiskan, B.; Alemdar, N.; Erciyes, A. T.; Yagci, Y. J Polym Sci Part A: Polym Chem 2010, 48, 4279-4284.

60 Kiskan, B.; Koz, B.; Yagci, Y. J Polym Sci Part A: Polym Chem 2009, 47, 6955-6961.

61 Ishida, H.; Sanders, D. P. Macromolecules 2000, 33, 8149-8157. 